Corundum deposits are known to occur all along the southern flanks of the Appalachian Chain, from the State of New York to that of Alabama, but it is in only a few localities, principally in North Carolina and Georgia, that the corundum has been extracted on any considerable scale. In I87I attention was first drawn to the deposits in North Carolina as a possible source of gems, and in 1878 mining operations were commenced to extract the abundant corundum of the district as an abrasive material. A great deal of secrecy has been maintained respecting the nature and extent of the corundum industry in the United States; but there appears to be no doubt that since I 878 a steady increase in the output of the corundum mines has been maintained.

The discovery of valuable deposits of corundum in the third of the localities noticed above, that of British Ontario, dates only from I 896 . But already there seems to be promise that the counties of Hastings, Renfrew and Peterborough in Eastern Ontario, may, at no distant date, yield large supplies of corundum to the manufacturer.

The Indian corundum is usually found among the gneissose and schistose rocks; the exact conditions under which the mineral makes its appearance will be better understood when the investigations, upon which Mr. Holland has been engaged for some years, are fully published. He has already shown that in some cases the corundum is found in connection with nepheline-bearing rocks, and a precisely similar association has been demonstrated for the corundiferous deposits of Eastern Ontario. The corundum of the Appalachian belt of the United States, however, as shown by Dr. J. H. Pratt, would appear in all cases to occur in the Peridotites (Dunites, Serpentine, \&c.), which are intrusive in crystalline schists, and especially in the zones of contact on the outer limits of those intrusive masses.

Corundum, the crystallised oxide of aluminium, has been prized from the earliest times on account of its hardness-which exceeds that of all other natural substances, with the exception of the diamond. In India, blocks of corundum and fragments mounted in tools have been used for grinding, perforating and engraving gems. For general abrasive purposes elsewhere, the rock emery (especially that of Naxos and the adjoining islands and mainland of Asia Minor) has long been preferred to corundum itself. The reason of this is that although emery has a far less "effective hardness," or power of abrading hard materials, than pure corundum, yet the ease with which it can be reduced to powder greatly facilitates its use.

Pure corundum, when freed from its adhering matrix of softer materials (mica, chlorite, \&c.), is crushed between rollers and sifted, the "corundum sand" thus formed having far more abrasive power than crushed emery. The chief use of corundum sand is for making corundum wheels; the cementing materials employed in making these wheels seem to be very varied. Shellac alone, or with the so-called "oxidised linseed oil," is one of the commonest materials employed, as in the so-called "red wheels." Silicate of soda is employed in the "silicate wheels," and india-rubber and other substances in the "vulcanite" or "black wheels"; while the cementing material in the "union wheel" is oxychloride of magnesia, and in the "tanite wheel" some form of a so-called "solution of leather," the process of manufacture being kept secret.

Pure corundum wheels are said to be at least twice as effective and durable as emery wheels. Corundum wheels are made in India, with the lac-resin as the cementing material.

Emery and corundum wheels may be regarded as rotary files, whose cutting points never grow dull. They are rapidly replacing files for cutting down metal surfaces, and taking the place of grindstones for sharpening tools.
The corundum grains throughout the wheel retain their cutting power, so that it can be worked until quite 90 per cent. of its weight has been worn off, while a file is useless before it has lost 5 per cent. of its weight. It has been estimated that to remove one pound weight of iron with a file costs $2 s$. $6 d$., while the same amount of work can be done with an emery or corundum wheel in about one-eighth of the time and at one-seventh of the cost. Compared with grindstones in grinding tools, experiments by some English firms show that the cost of the emery wheel is about one-fifth, and the time only one-half of that required by the use of the old grindstone, and at the same time the danger of bursting during rapid revolution, which is such a common accident with the latter tool, is practically abolished.

The corundum wheel is said to be twice as effective as the emery wheel, while its cost is only I 5 per cent. more.

It will be seen irom these statements that there cannot fail to be a great futture for wheels made from corundum and similar materials.

As is pointed out by Mr. Holland, corundum is the richest ore of the valuable metal aluminium. So long, however, as abundant supplies of bauxite (impure hydrated oxides of aluminium) can be obtained, it is scarcely likely that the hard and intractable corundum will be used for the extraction of the metal. The time may, however, come when such a use will be made of the material, which is now almost wholly sought for abrasive purposes.

\section{MULTIPLE VISION.}

$\mathrm{T} \mathrm{T}$ is well known that, owing to what is termed irregular astigmatism, a small bright object, for which the eye is not accommodated, often presents a multiform appearance, the number of separate images perceived varying in different cases from about six to fifteen.

Irregular astigmatism, to which every one is in some degree a victim, can be easily demonstrated in the following manner. With the point of a fine needle a very small hole is pricked in a sheet of tin-foil ; this is held up to the light, and the hole is looked at with one eye, the other being closed. Even at the distance of most distinct vision-ten inches, or thereabouts--there will probably be a ragged appearance about the perforation, as if it were not perfectly round. But if the tin-foil be brought an inch or two nearer to the eye, the perforation will not seem to be even approximately circular ; it will generally assume the form of a little star with six or more pointed rays. The form of the star is not often the same for the right eye as for the left; but if several holes be pricked in the tin-foil, all the stars as seen by the same eye will appear to be formed after the same model, though some may be larger or brighter than others.

If the luminosity of the source of light is sufficiently diminished by screening with a coloured glass, or otherwise, the star will be seen to consist of several distinct images of the hole superposed upon an irregular nebulous patch. Seven such images can generally be perceiveda central one surrounded by six others, but sometimes there may be more. This and other allied phenomena exhibited by a healthy eye are commonly attributed to the fact that the crystalline lens is composed of several sections connected by radial sutures, six or more in number, which occur upon the two surfaces of the lens.

Some observations described in a recent communication to the Royal Society (Proc. Roy. Soc., January 1899) indicate that under certain conditions the number of independent images due to a single luminous point is far greater than could be accounted for in this way; there may, in fact, be several hundreds, and their formation probably arises from the cellular structure of the transparent media of the eye.

NO. I 537 , VOL. 59] 
In my earlier experiments the luminous object consisted of a small bright disc, but it was soon found desirable to employ a source of light having a more distinctive and conspicuous form than that of a simple circle, and after several trials an excellent object was found in the horseshoe-shaped filament of an electric lamp. The lamp should be dimmed, either by placing coloured glasses before it, or, preferably, by inserting a resistance. An Edison-Swan 50-volt lamp of 8 candlepower has a suitable filament, and may advantageously

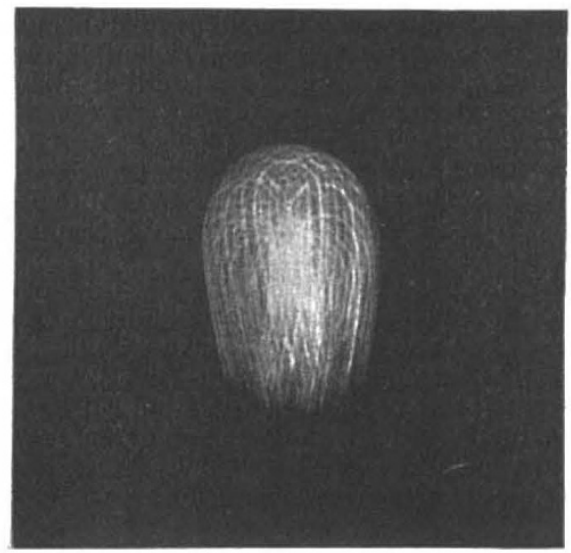

FIG. I.

be connected in series with one or two of the lamps ordinarily used on the circuit. Most electric lamps have looped filaments, and are not so well adapted for the observation.

When the dinmmed lamp is looked at from a distance of a few feet through a lens of about 6 inches focal length, held close to the eye, the patch of luminosity formed upon the retina appears to be made up of a crowd of separate images of the filament, some being

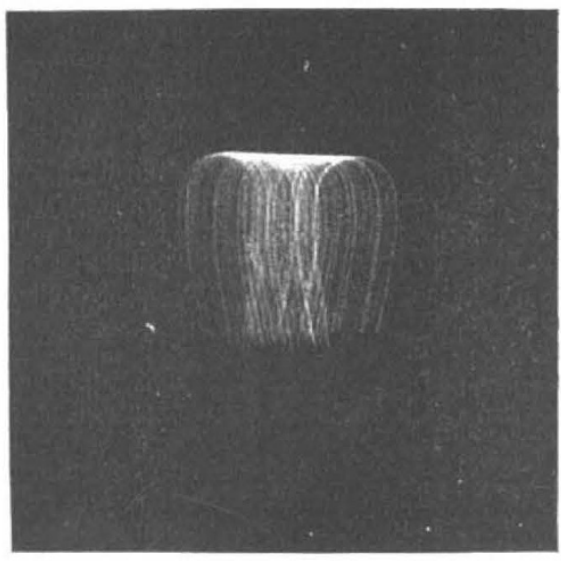

FIG. 2.

brighter than others, as represented in Fig..$^{1}$ When the observer is near the lamp, the number of images is comparatively small ; as he retires, it gradually inçreases, but after a certain distance has been reached the definition of the images becomes impaired, and they can no longer be easily distinguished. The method of observation as thus described may obviously be varied,

1 The photographs, Figs. I to 4 , are too delicate for satisfactory reproduction. In the originals each picture is easily seen to be entirely composed of separate images of the filament.

NO. 1537 , VOL. 59] and, indeed, an experienced observer can put his eye sufficiently out of focus without the aid of any lens.

To assist in analysing the luminous field, an adjustable slit, taken from a spectroscope, was interposed between the eye and the lens. The appearance presented by the filament when the slit was made $\frac{1}{80}$ inch $\left(0^{\circ} 3 \mathrm{~mm}\right.$.) wide, is very well imitated in Figs. 2, 3 and 4 , which show the effect with the slit in horizontal, vertical and intermediate positions. The imitation was produced by photographing the lamp by means of a lens covered with two layers of

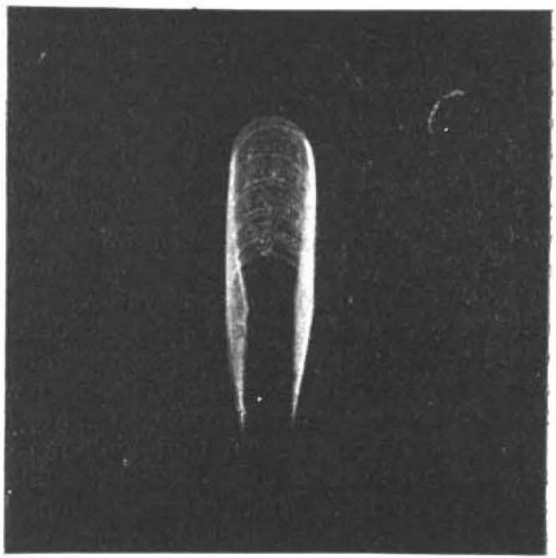

FIG. 3.

gauze, the one containing 75 meshes to the linear inch, the other 50 ; a slit ${ }_{25}^{1}$ inch ( $1 \mathrm{~mm}$.) in width was placed before the lens.

An attempt was made to count the greatest number of images that could be seen with fair distinctness. The whole of the filament was screened from view except a short portion of one limb, which was viewed from a distance of about 8 feet through a horizontal slit and a lens of 5 inches focus. According to the estimates of

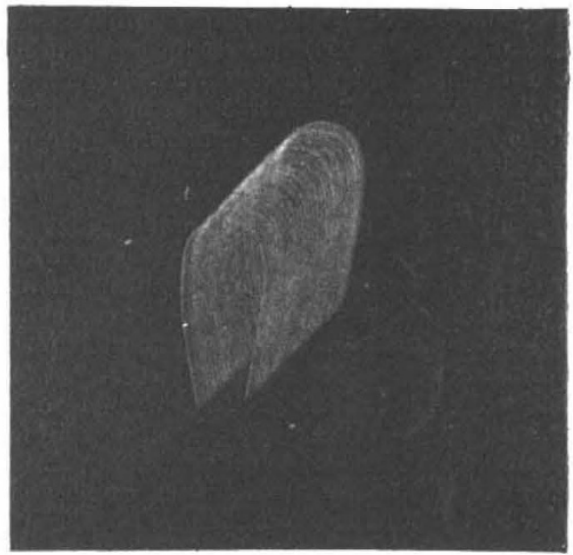

FIG. 4.

several different observers, the number of images was greater than 20 and less than 30 (whence it is calculated that without the slit there would be some 500). Exact enumeration is perhaps impossible, for though at the first glance one receives the impression that the number is quite definite and probably about 25 , closer examination shows that it is often very difficult to localise the line of demarcation between successive images.

If the distance between the eye and the incandescent filament is much more than 8 feet, or if a lens of shorter 
focus is employed, the multiple images become blurred and indistinct. The appearance ultimately presented is that of a band of light crossed by a very large numberprobably 400 or $500-$ of hazy dark lines at right angles to its length. These might be produced by some structure in or near the crystalline lens or the cornea composed of elements measuring about $\frac{1}{000}$ inch in length or breadth.

I do not know of any simple structure sufficiently coarse-grained to account for the images of which 25 , or thereabouts, occur in a row. The mesh of a network which would explain these should be about ${ }^{-\frac{1}{2}}$ inch $(0.2 \mathrm{~mm}$.) in length, and nothing of the kind is, I believe, to be found in the eye. Probably, however, the effect is a composite one, like that of the two pieces of gauze used in photographing the lamp. If light passed through two superposed nets having fine meshes, dark bands would generally be produced, which would take the form of a network of a coarser mesh than those of the nets themselves-possibly much coarser, as would be the case if the two nets were nearly alike in structure. SHELFORD BIDWELL.

\section{NEW STAR IN SAGITTARIUS.}

A CIRCULAR (No. 42) from the Harvard College Observatory, informs us of the detection of a new star in the constellation Sagittarius by Mrs. Fleming, during the examination of the Draper Memorial photographs. The date of appearance is not yet definitely determined, but was either in the latter part of the year I 897 or the early part of 1898 . The approximate position for 1900 , as found from the Durchmusterung Chart of the region, is

$$
\text { R.A. }=18 \mathrm{~h} \cdot 56 \mathrm{~m} \cdot 12 \cdot 2 \mathrm{~s} . \text { Decl. }=-13^{\circ} 18^{\prime} 16^{\prime \prime} .
$$

The star was too faint to be photographed on eightyseven plates exposed during the period 1888 September 5 to 1897 October 23 , even though the last of the plates taken in 1897 showed stars down to the 15 th magnitude, the instrument being the 24 -inch Bruce telescope at Arequipa. The Nova first appears on eight plates taken in March and April of last year-four at Arequipa with the 8-inch Bache telescope and four at Cambridge, Mass., with the 8-inch Draper telescope, both of these instrunients being provided with prisms outside the objectives. It may be added that both the lenses are doublets. The estimated magnitudes are from comparisons with adjacent stars, and are to be regarded as approximate, as the star was away from the centre of plate in several cases. On March 8, 1898 , the magnitude is given as 4.7 ; while on April 29,1898 , it is 8.2 .

The Nova has of course been detected from the peculiarity of its spectrum, which consists chiefly of bright lines. The best photograph was obtained on April 19, 1898 , with an exposure of sixty minutes, the magnitude of the star then being 8.2 . The spectrum, 3 $\mathrm{mm}$. in length, shows the lines $\mathrm{H}_{\beta}, \mathrm{H}_{\gamma}, \mathrm{H}_{\delta}, \mathrm{H}_{\epsilon}, \mathrm{H}, \mathrm{H}_{\eta}$, and probably $\mathrm{H}_{\theta}$, due to hydrogen, bright. A broad band at $\lambda 4643$ is also bright, and narrow bright lines are present at $\lambda \lambda$ 4029, 4I 79, 4238, 4276, 4459, and 4536, these latter appearing to be identical with lines at corresponding positions in the spectrum of Nova Aurigæ. The strongest dark line is at $\lambda$ 406o. As in the Novæ Persei, Aurigæ, Normæ, and Corinæ, the line $\mathrm{H}_{\epsilon}$ is bright; while in variables of long period this line is always dark, being possibly obscured by the neighbouring broad calcium line $\mathrm{H}$. This difference may serve to distinguish between Novæ and variables. The accompanying dark lines on the more refrangible edges of the bright bands of Novæ Aurigæ, Normæ, and Corinæ are not visible in the spectrum of Nova Sagittarii. The calcium line $\mathrm{K}$ is also invisible. In the photograph ob- tained two days later-1898 April $2 \mathrm{I}$-certain marked differences are noted. The broad dark line $\lambda$ 4060 has disappeared, and a narrow bright line appears at $\lambda$ 5005, possibly identical with the chief nebula line at $\lambda .5007$. The hydrogen lines appear to be narrower and more intense.

Plates exposed at Arequipa on October 7 and 8, 1898 , but not yet examined, will furnish important information as to the rate of diminution of the light of the Nova. On the morning of March 13 of this year, Prof. O. C. Wendell examined the star with the photometer at Cambridge, and found that its magnitude was then I I 37. Visual examination showed its light to be nearly mono chromatic, with a faint continuous spectrum, in this respect resembling other Novæ that have preceded it, in having changed to a gaseous nebula. This change had evidently begun at the time of the photograph taken on 1898 April 21 , showing the line $\lambda$ 5005.

It is interesting to note that of the six new stars which have been discovered since 1885 , five have been found by Mrs. Fleming during her detailed examinations of the Henry Draper Memorial photographs of stellar spectra.

During the last four hundred years fifteen stars have appeared which may be regarded as Novæe, and, in general, have been found in the vicinity of the central line of the Milky Way, their average galactic latitude being about $\mathrm{II}^{\circ} \cdot 2$. Nova Andromedæ and Nova Centauri showed no bright lines in their spectra, and, if these be excepted, the average galactic latitude of the remaining thirteen is $9^{\circ}$ o. Of these Nova Coronæ is the only new star with bright lines in its spectrum which has appeared far from the central line of the galaxy, its latitude being $46^{\circ} .8$. If this also be excepted, the average galactic latitude of the other twelve is reduced to $5^{\circ} .8$. It is thus to be inferred that there is some association between the galaxy and the new stars whose spectra contain bright lines, as the probability that such a distribution is due to accident is extremely small.

\section{FRANZ RITTER VON HAUER.}

A DISTINGUISHED Austrian geologist has passed away in the person of Dr. Franz Ritter von Hauer, the Intendant of the Royal Imperial Natural History Museum of Vienna. Von Hauer was born in Vienna on January 30,1822 , and received his education partly in that city, and subsequently at the mining academy of Schemnitz. In 1846 he became assistant to Wilhelm von Haidinger, who was then councillor of mines and lecturer on mineralogy in Vienna. Later on, in 1849 , when Von Haidinger was appointed director of the then newlyestablished Imperial Geological Institute, Von Hauer was engaged as geologist, and he took a leading part in the work of the survey, succeeding to the post of director on the retirement of his chief in 1866.

Among his special geological works, those on the Cephalopoda of the Triassic and Jurassic formations of eastern. Alpine regions are the most numerous and important ; but he contributed other papers and works on mineralogy and applied geology.

His most important general work was that of the geological map of the Austro-Hungarian monarchy, which was issued in twelve sheets, $1867-7 \mathrm{I}$, and of which a fourth edition, including Bosnia and Montenegro, was published in I884. His explanatory pamphlets relating to this great map have been described as "models of concise description," while his general manual of Austrian geology, published in 1875 , "is the best guide we have
to some of the most interesting parts of Central and Eastern Europe." The remarks quoted were made by Mr. R. Etheridge in 1882 , when as president of the Geological Society he forwarded to Von Hauer the No. I 537 , vOL. 59$]$ 